\title{
LIXO E RECICLAGEM: A PERCEPÇÃO AMBIENTAL DE ESTUDANTES DE ESCOLAS PÚBLICAS E PRIVADAS DO MUNICÍPIO DE BOM JESUS DO ITABAPOANA (RJ)
}

\author{
José Natal Correia \\ Licenciado em Ciências Biológicas /CEDERJ, Polo Bom Jesus do Itabapoana/RJ \\ josenatal100@yahoo.com.br \\ Caio A. Figueiredo-de-Andrade \\ Mestre em Ciências Biológicas (Zoologia)/CEDERJ, Polo Bom Jesus do Itabapoana/RJ \\ caio.bio@hotmail.com \\ Nathália Bastos Lima \\ Doutora em Biociências e Biotecnologia/CEDERJ, Polo Bom Jesus do Itabapoana/RJ \\ nathalia.bioquimica@gmail.com
}

\section{RESUMO}

Lixo e reciclagem são temas relevantes para a sociedade em vista dos grandes problemas ambientais causados pelo homem e as suas conseqüências para a natureza. Este trabalho teve o intuito de avaliar a percepção de estudantes de escolas públicas e particulares sobre o tema lixo e reciclagem. Para isso, foi aplicado um questionário misto e estruturado para alunos do $9^{\circ}$ ano do Ensino Fundamental do Município de Bom Jesus do Itabapoana (RJ), totalizando 144 alunos de escolas da rede pública e privada. Foi observado que a maioria dos alunos de ambas as modalidades de ensino não souberam conceituar corretamente os termos lixo e reciclagem, mostrando que, apesar do tema ser abordado pelos meios de comunicação, poucos alunos se atentam para o conhecimento disponível. Muitos estudantes confundiram termos freqüentemente abordados pela mídia, como por exemplo, definindo reciclagem como coleta seletiva. Muitos alunos responderam corretamente sobre quais materiais podem ou não ser reciclados, mostrando que os mesmos detêm algum conhecimento sobre o tema, apesar deste poder ser mais bem trabalhado nas escolas. Os alunos não demonstraram percepção de que eles mesmos estão inseridos nos problemas ambientais, mostrando a necessidade de um trabalho mais eficaz relacionado à educação ambiental nas escolas.

Palavras-chave: Educação Ambiental; Alunos; Bom Jesus do Itabapoana; Escolas Públicas e Privadas.

\begin{abstract}
Garbage and recycling are important issues to thinking about for our society, bearing in mind the huge environmental problems caused by people and their consequences to the nature. This research aimed to evaluate te the comprehension of students from public and private schools about the themes garbage and recycling. For that, it was applied a questionnaire to students from the $9^{\circ}$ year of the High School form the municipality of Bom Jesus do Itabapoana, totalizing 144 students from public and private schools. We observed that the most of students could not concept "garbage" and "recycling" correctly, showing us that despite of the theme is being presented frequently by the means of communication, few students are wakeful for the knowledge available. It
\end{abstract}

Persp. online: hum. \& sociais aplicada., Campos dos Goytacazes, 15 (6),53-65, 2016

seer.perspectivasonline.com.br 
was also observed that the students mistaken terms frequently approached by the media as, for example, defining recycling as the same as selective waste collection. Many students answered correctly about which materials can or cannot be recycled, indicating that they have some knowledge about that, but it could be better approach by the schools. It was founded out that the students showed no perception that themselves are within the environmental problems, indicating that a more efficient work about environmental education in the schools.

Palavras-chave: Environmental Education; Students; Bom Jesus do Itabapoana; Public and Private Schools.

\section{INTRODUÇÃO}

Desde o início da sua história até os dias de hoje, o homem produz resíduos originados de suas atividades. Na pré-história, o ser humano era nômade e a sua sobrevivência era dependente da coleta de vegetais, da caça e da pesca. Desta forma, os restos de sua alimentação eram compostos basicamente por resíduos orgânicos, que, ao serem deixados para trás, retornavam ao processo natural de ciclagem de nutrientes (ABREU \& PALHARES, 2006). Com o advento da agricultura e, posteriormente, da pecuária, foram formando-se grupos sociais sedentários, não havendo mais a necessidade do deslocamento de um local para outro quando o alimento era escasso. Desta forma, foram se estabelecendo as comunidades, que, posteriormente deram origem às cidades. Com o passar do tempo, a população foi aumentando, e, conseqüentemente, os resíduos produzidos por ela também aumentaram (ABREU \& PALHARES, 2006).

A partir da Revolução Industrial, no século XVIII, iniciou-se a fabricação de produtos industrializados e artificiais, acarretando num maior consumo destes, o que contribuiu para o aumento do desperdício (FILHO, 2006). Então começaram a surgir os primeiros problemas relacionados ao lixo jogado nos rios e mares, enterrados ou deixados a céu aberto em locais afastados (FILHO, 2006).

Somente a partir da década de 70, tanto no Brasil quanto outros países, o lixo começou a ter seu conceito debatido e ampliado, preocupando ecologistas, principalmente por causa da crescente industrialização (CRUZ \& MARQUES, 2007). Com o fim da guerra fria, após a década de 80 , diversos problemas ambientais foram notados em todo mundo, inclusive o abuso na produção de lixo pelas grandes cidades. Com o crescimento da economia americana e com as novas tecnologias atreladas ao petróleo, o problema se intensificou, acarretando no surgimento dos materiais sintéticos (como o plástico), que substituíram grande parte das matérias-primas naturais antes utilizadas (FILHO, 2006).

A destinação incorreta do lixo, principalmente nas grandes cidades, gera diversos problemas sociais, ambientais e econômicos. O lixo atrai uma série de vetores de doenças e também serve como local para proliferação de microorganismos patogênicos, além de causar a poluição do solo, do lençol freático e do ar (MARODIN et al., 2004). Grandes quantias são gastas pelos governos para a correção destes problemas, que poderiam ser diminuídos se houvesse uma conscientização para produzir-se menos lixo e reciclarem-se mais materiais.

Extinguir a produção de lixo é impossível, contudo, a Política dos 5Rs foi idealizada para amenizar estes problemas causados pelo lixo (ZANI, 2010):

Repensar: Consumir de forma consciente, escolher principalmente os produtos provenientes de matéria-prima de fácil decomposição.

Recusar: Evitar materiais sintéticos, que demoram anos para se decompor ou que causem danos ambientais.

Persp. online: hum. \& sociais aplicada., Campos dos Goytacazes, 15 (6),53-65, 2016

seer.perspectivasonline.com.br 
Reduzir - Consumir produtos que podem ser usados mais de uma vez, com menos embalagens, durabilidade maior, procurar usar racionalmente materiais de origem natural, etc.

Reutilizar: Procurar reutilizar tudo que for possível, principalmente os materiais que mais contribuem para poluição do meio ambiente, como os sacos plásticos, garrafas pet, potes de sorvete, entre outros, que demoram milhares de anos para se decompor.

Reciclar: É um meio de recuperar-se o material destinado ao lixo e utilizá-lo para fabricação de novos produtos, seja artesanal ou industrial. A reciclagem é uma forma de reaproveitar materiais que usamos diariamente, sendo necessário o desenvolvimento de novas técnicas para reciclar materiais, o que se torna uma fonte de trabalho para várias pessoas, contribuindo para a geração de empregos.

A reciclagem é um dos destinos finais mais ecológicos e lucrativos para o lixo. Muitos países estão investindo cada vez mais no desenvolvimento de novas técnicas de reciclagem, pois, para cada material que pode ser reaproveitado existe uma maneira correta de reciclagem, e sendo assim, a coleta seletiva do lixo é muito importante neste processo (BURGIERMAN, 2010). A coleta seletiva é um dos primeiros passos para a reciclagem, tendo como objetivo a separação e classificação do lixo, em diferentes categorias. Os materiais são classificados em orgânicos (frutas, restos de comida, verduras, esterco, apara de gramas, etc.) e materiais inorgânicos (vidro, papel, metais, plásticos), sendo separados em recipientes de cores diferentes, característicos para cada tipo de material, onde o verde seria para o descarte de vidros, vermelho para plásticos, amarelo para metais e azul para papéis (ROBINSON, 1998).

Nas últimas décadas, ocorreram grandes mudanças, tanto nos campos socioeconômico, político e cultural, quanto científico e tecnológico. No final dos anos 80, surgiu a "Era da Informação" (GADOTTI, 2000). Segundo Paulo Freire (2000) "este era um momento novo e rico de possibilidades, por isso não se poderia falar do futuro da Educação sem certa dose de cautela". Os educadores, diante dessas rápidas mudanças na sociedade, na tecnologia e na economia, devem fazer um balanço sobre práticas e teorias que atravessaram os tempos (GADOTTI, 2000).

Nos últimos anos, a Educação Ambiental tem sido a ferramenta fomentadora de ações com o intuito de colaborar na transformação socioambiental. A escola foi um dos primeiros espaços a receber esse processo, tendo uma parte na responsabilidade de se melhorar a qualidade de vida, através da informação e conscientização das pessoas (SEGURA, 2001). Assim, é importante que o ambiente escolar esteja empenhado em realizar ações voltadas para a Educação Ambiental, onde professores realmente trabalham sobre o tema com os alunos, desenvolvendo projetos de maneira transversal para que sejam formados cidadãos com conduta responsável em relação ao meio ambiente. Dessa forma, a escola estará transmitindo o conhecimento de uma maneira geral, abordando o tema lixo e reciclagem em diferentes contextos, permitindo que o aluno o insira em seu cotidiano.

O objetivo do presente trabalho é analisar a percepção dos alunos de $9^{\circ}$ ano de escolas públicas e particulares do município de Bom Jesus do Itabapoana (RJ) com relação ao lixo e a importância da reciclagem, comparar as possíveis disparidades entre os conhecimentos adquiridos pelos alunos de ambos os sistemas de ensino, obter dados relacionados à compreensão dos alunos sobre o tema abordado e como este tópico é trabalhado nas escolas do município.

\section{METODOLOGIA}

\subsection{Caracterização da área de estudo}

O município de Bom Jesus do Itabapoana, localizado na região Noroeste Fluminense no Estado do Rio de

Persp. online: hum. \& sociais aplicada., Campos dos Goytacazes, 15 (6),53-65, 2016

seer.perspectivasonline.com.br 
Janeiro, possui uma área total de $599,4 \mathrm{~km}^{2}$ e uma população de 35.133 habitantes. É banhado pelo Rio Itabapoana, que nasce na serra do Caparaó - MG (TCE, 2005). A cidade não conta com uma usina de reciclagem, mas possui locais que recebem materiais recolhidos da coleta seletiva, para serem enviados para o município de Campos dos Goytacazes (RJ), e outros municípios.

\subsection{Aplicação dos questionários}

Para realizar a avaliação dos conhecimentos da população estudantil, foi aplicado um questionário misto e estruturado (anexo 1) a estudantes de 6 escolas do município de Bom Jesus do Itabapoana, sendo três escolas públicas e três escolas particulares. O questionário foi aplicado a 67 alunos de escolas públicas e a 77 alunos de escolas particulares, totalizando 144 alunos do $9^{\circ}$ ano do Ensino Fundamental. O questionário foi aplicado em sala de aula, com a permissão da direção escolar, durante o período normal de aulas e sem interferência dos professores.

\section{RESULTADOS E DISCUSSÃO}

O conceito de lixo se refere aos diversos resíduos sólidos produzidos a partir de atividades humanas, sendo mais utilizado para definir os resíduos produzidos em residências (FADINI \& FADINI, 2001). Com base neste conceito, apenas $15 \%$ dos alunos de escolas públicas e $14 \%$ dos alunos de escolas privadas souberam responder adequadamente à questão 1: "Na sua opinião , o que é Lixo?". Alguns exemplos de respostas incorretas ou parcialmente corretas foram as seguintes: "Um produto tóxico", "Sujeira", "É Tudo aquilo que consumimos e jogamos fora", "É tudo que o ser humano produz", "Restos orgânicos e também inorgânicos, que se não forem tratados corretamente, causam grandes problemas à saúde e ao meio ambiente". A maioria dos discentes não sabe realmente definir o que é lixo, uma vez que mais da metade do total de alunos de ambos os sistemas escolares não conceituou o termo lixo adequadamente (cerca de $62 \%$ dos alunos de escolas públicas e $72 \%$ de privadas), como mostra a figura 1 . O tema reciclagem, apesar de ser um assunto bastante abordado atualmente, ainda passa despercebido por boa parte dos alunos entrevistados. Este é um dado estarrecedor, que nos mostra uma grande necessidade de abordar esta questão com maior frequência em sala de aula, tanto em instituições de ensino público, quanto de ensino privado.
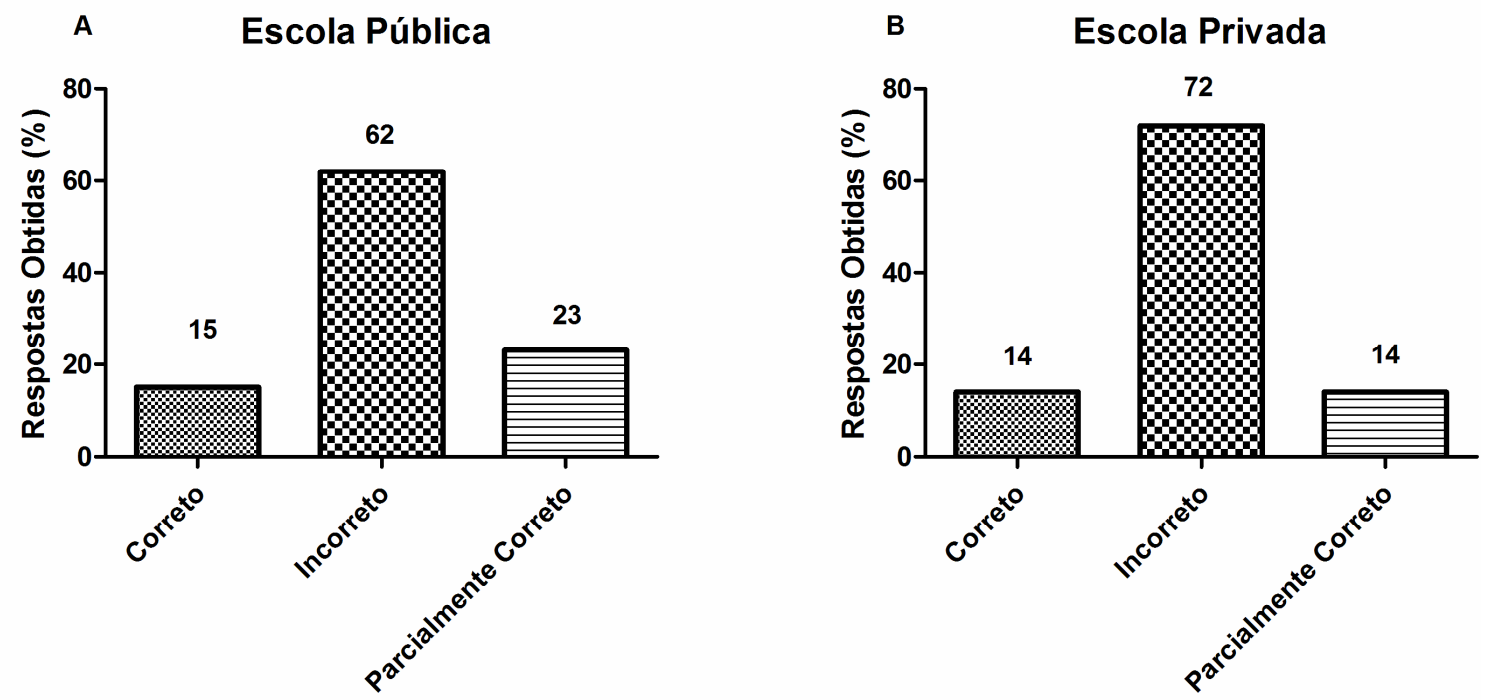

Figura 1. Gráfico correspondente às respostas dos alunos em relação à Questão 01: Na sua opinião, o que é lixo?

Persp. online: hum. \& sociais aplicada., Campos dos Goytacazes, 15 (6),53-65, 2016

seer.perspectivasonline.com.br 
Com relação à questão $2,46 \%$ dos alunos das escolas públicas afirmaram que existe uma relação entre a quantidade de lixo gerada em uma cidade e a saúde das pessoas, enquanto que, em escolas particulares, apenas $33 \%$ concordaram com esta correlação (figura 2). Também foi observado que um grande número de alunos de escolas públicas e privadas (42\% e $62 \%$, respectivamente) acreditam que apenas em alguns casos a quantidade de lixo gerada afeta a saúde da população (figura 2). Inúmeros estudos apresentam uma correlação positiva entre a falta de saneamento e prejuízos à saúde (ESREY et al., 1991). Os resíduos sólidos produzidos nos centros urbanos contêm resíduos domésticos e comerciais, além de lixo industrial, sendo compostos por uma mistura complexa das mais variadas substâncias, muitas delas representando perigos para a saúde (GOUVEIA \& PRADO, 2010).

Quando questionados se acreditavam que o lixo poderia causar algum dano ao meio ambiente, a maioria dos alunos respondeu positivamente, com 97\% das afirmativas em escolas públicas e 99\% em escolas privadas (dados não mostrados), o que nos mostra que eles têm consciência disto, e que, provavelmente, estas respostas são um reflexo da influência dos meios de comunicação sobre os entrevistados, uma vez que o tema "meio ambiente" tem cada vez mais destaque da mídia.
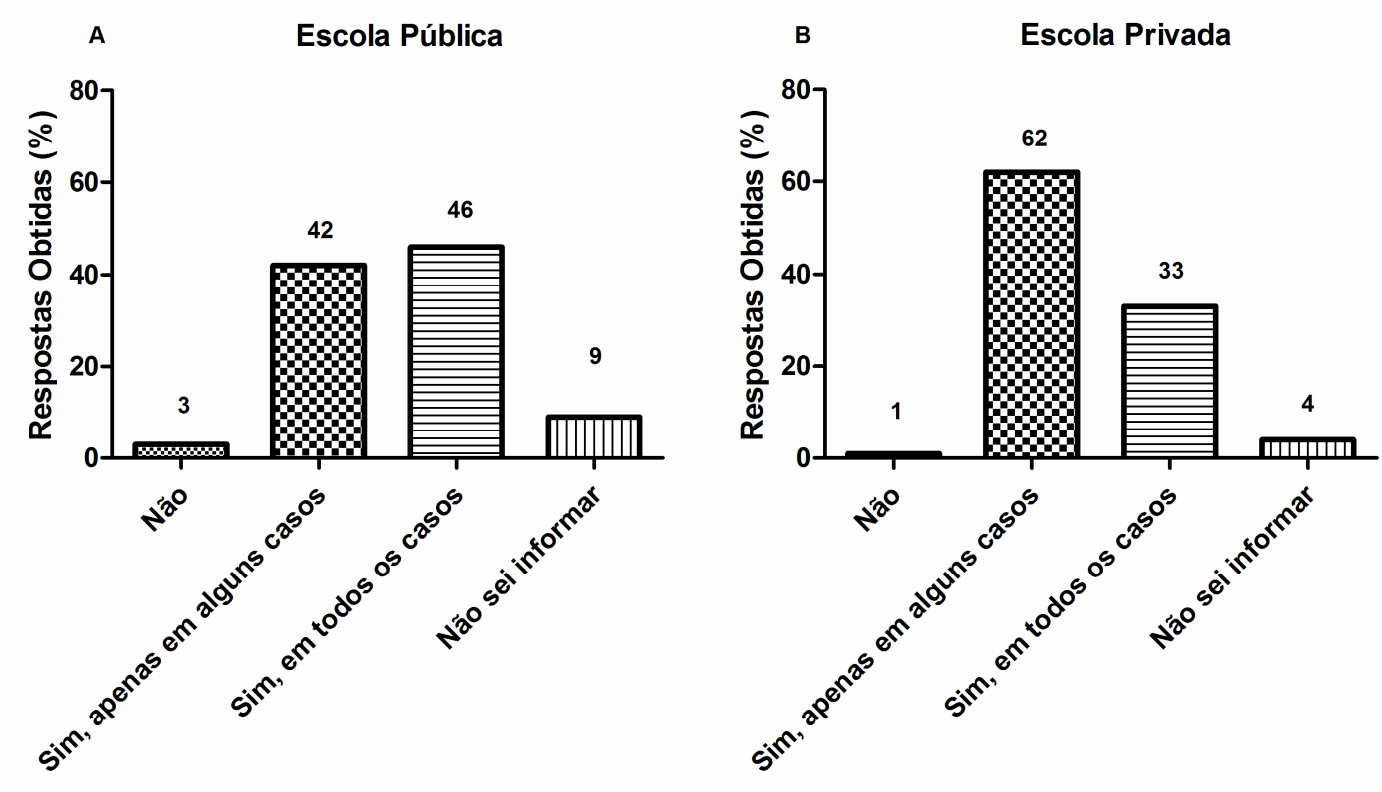

Figura 2: Gráfico correspondente às respostas dos alunos em relação à questão 02: Você acha que há alguma relação entre a quantidade de lixo gerada em uma cidade e a saúde das pessoas que vivem naquele local?

Porém, quando perguntados se eles se consideravam causadores de algum dano ao ambiente $26 \%$ dos alunos do ensino público e $23 \%$ dos alunos do ensino privado não se consideravam causadores de danos ao meio ambiente (figura 3), um número relativamente alto. Dentre os alunos que se consideravam causadores de danos ambientais, as principais respostas foram: "Sim, o consumo de materiais como garrafas PET, latinhas e sacolas"; "Muitas atividades do dia-a-dia causam danos, até mesmo acender a luz"; "Por não estar reciclando"; "Jogando lixo na rua por falta de achar uma lixeira". Dentre as respostas afirmativas, 51\% dos alunos de ambos os

Persp. online: hum. \& sociais aplicada., Campos dos Goytacazes, 15 (6),53-65, 2016

seer.perspectivasonline.com.br 
sistemas de ensino acreditam que danificam o meio ambiente ao jogar papel no chão, como mostra a figura 3 . A partir de tais afirmativas, nota-se o que os alunos percebem a problemática do lixo como algo estritamente local e não global fazendo-nos perceber que os danos ambientais maiores, como poluição das águas, efeito estufa, degradação da camada de ozônio, etc., estão muito distantes do cotidiano destes alunos, não sendo assim uma preocupação real frente a este problema (MUCELIN \& BELLINI, 2008).
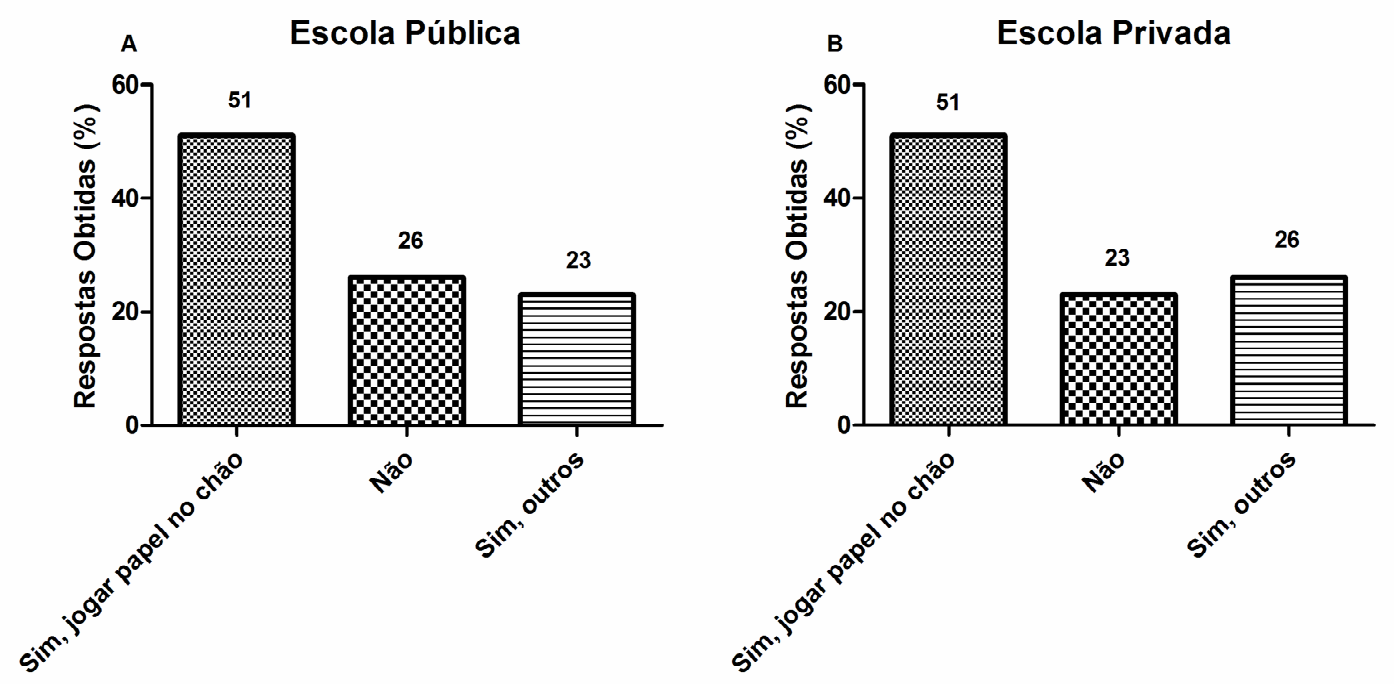

Figura 3: Gráfico correspondente às respostas dos alunos em relação à questão 04: No seu dia-a-dia, você se considera causador de algum dano ao meio ambiente? Caso, sim, quais?
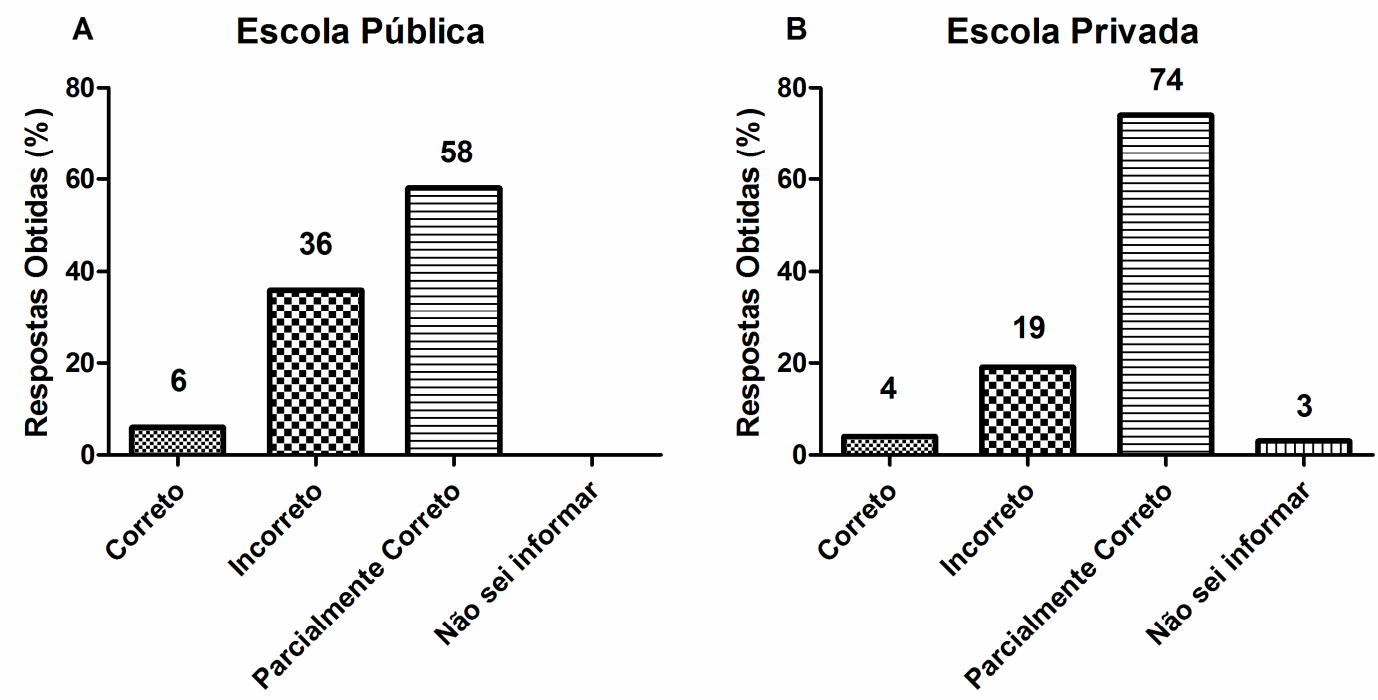

Figura 4: Gráfico correspondente às respostas dos alunos em relação à questão 05: Na sua opinião, o que é reciclagem? Você sabe para que serve a reciclagem?

Persp. online: hum. \& sociais aplicada., Campos dos Goytacazes, 15 (6),53-65, 2016

seer.perspectivasonline.com.br 
A reciclagem pode ser definida como conjunto de técnicas que busca reaproveitar materiais jogados no lixo, para que eles se tornem novamente úteis e que possam ser reinseridos no mercado (RUDDEK \& MUZZILLO, 2007). Baseado neste conceito, apenas 4\% dos alunos de escola privada e apenas $6 \%$ dos alunos da escola pública respondeu corretamente quanto ao conceito de reciclagem, como mostra a figura 4, mostrando a necessidade das escolas trabalharem tal tema em sala de aula. Algumas respostas para tal pergunta foram: "É um modo de se livrar do lixo sem dano algum"; "Reciclar é fazer do inútil algo útil"; "É o reaproveitamento do lixo substituindo por um produto novo, diminuindo seu impacto ambiental". Foi observado também que os alunos de escolas públicas e privadas confundiram o tema reciclagem com coleta seletiva, pois também foram obtidas respostas como "Separar materiais que podem ser reaproveitados".

Quando os alunos foram requisitados para responder a questão 06 do questionário, intitulada: "Que materiais você considera que possam ser reciclados?", obtivemos uma grande diversidade de respostas, como mostra a figura 5. Foi visto que entre 70 e $73 \%$ dos alunos da rede privada e entre 58 e $66 \%$ da rede pública responderam corretamente que folhas de caderno, caixas de leite e latas de refrigerante são materiais recicláveis. Com relação ao item "potes de vidro", apenas $42 \%$ dos alunos de escolas públicas e $54 \%$ de escolas privadas responderam que são recicláveis. Já para o item "canos", os alunos de escolas privadas obtiveram maior porcentagem de acertos (69\%) em relação aos alunos de escolas privadas (44\%). Com relação a "copos descartáveis", não foi observada uma grande diferença nos padrões de respostas entre alunos de escolas públicas e particulares (61\% e 57\%, respectivamente). Os itens "Pregos e parafusos" e "Lâmpadas incandescentes" foram os itens recicláveis com os mais baixos índices de respostas afirmativas, para ambos os sistemas de ensino (abaixo de 35\%). Já os itens não-recicláveis "Guardanapos", "Pilhas e baterias", "Lâmpadas fluorescentes", "Fita crepe" e "Adesivos" foram considerados erroneamente recicláveis por entre 19 e $23 \%$ dos alunos de escolas privadas, e entre 11 e $24 \%$ dos alunos de escolas públicas. Os resultados mostrados na figura 5 nos revelam que os alunos apresentam certo conhecimento com relação aos materiais que podem ou não ser reciclados, onde é possível observar que a maioria das respostas corretas são para aqueles materiais que são abordados com mais frequência pelos meios de comunicação.

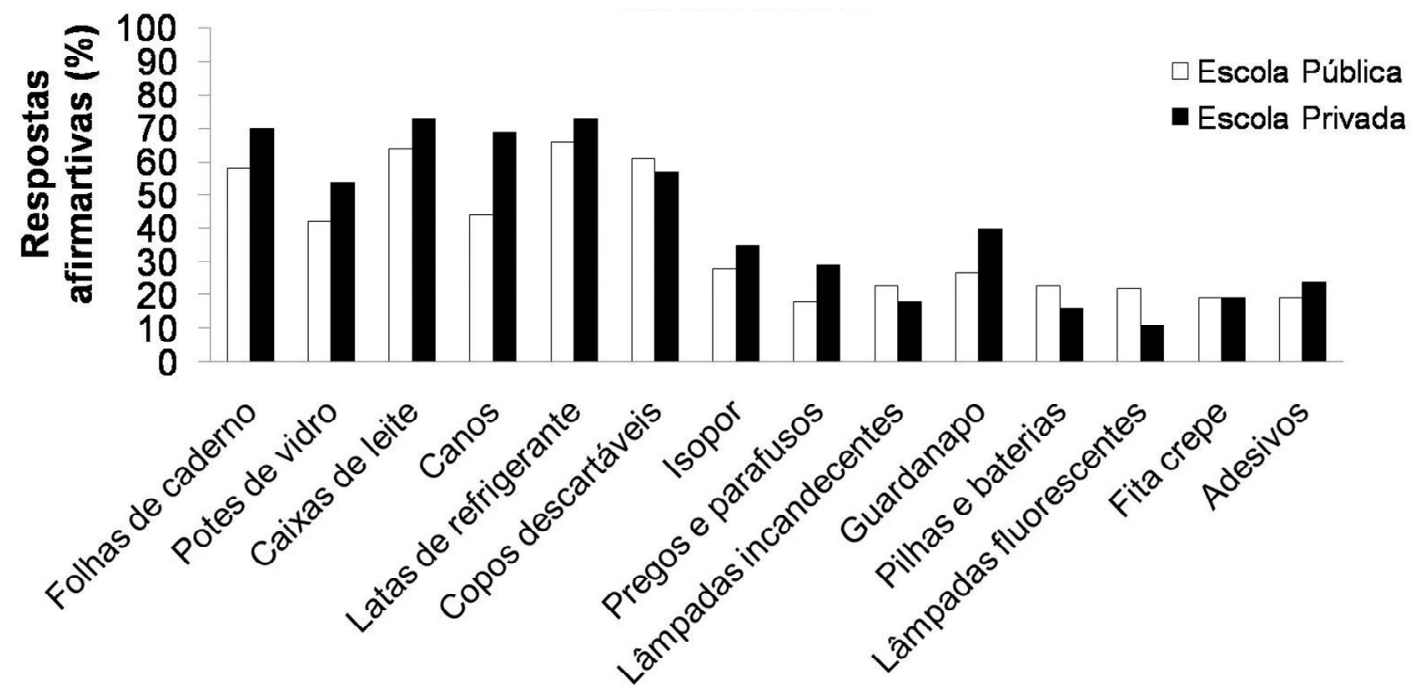

Materiais apresentados

Figura 5: Gráfico correspondente às respostas dos alunos em relação à questão 06: Que materiais você considera que possam ser reciclados? As opiniões dos alunos da escola pública e privada estão juntas no mesmo gráfico.

Persp. online: hum. \& sociais aplicada., Campos dos Goytacazes, 15 (6),53-65, 2016

seer.perspectivasonline.com.br 
O termo "coleta seletiva" consiste na separação qualitativa dos materiais considerados lixo daqueles que podem ser reaproveitáveis, tais como papel, plástico, metal, vidro e matéria orgânica (DEBORTOLI \& BORBA, 2006). Quando foram abordados sobre o conceito de coleta seletiva (questão 07 do questionário) cerca de $40 \%$ dos alunos de ambos os sistemas de ensino responderam que já ouviram falar desse tema na escola (figura 6), o que é considerado um fator positivo, pois, em teoria, a escola é o local onde há o fornecimento de informações reais e de relevância sobre este tema. Porém, a influência da mídia pode ser mais abrangente, uma vez que este meio de comunicação não atinge somente o aluno, mas também a sua família, podendo, dessa maneira, influenciar mudanças de costumes e atitudes. De acordo com os PCN (1997) os conteúdos relacionados ao Meio Ambiente, Lixo e Reciclagem devem ser integrados ao currículo através da transversalidade, devendo ser tratados nas diversas áreas do conhecimento, de modo a impregnar toda a prática educativa e, ao mesmo tempo, criar uma visão global e abrangente da questão ambiental.
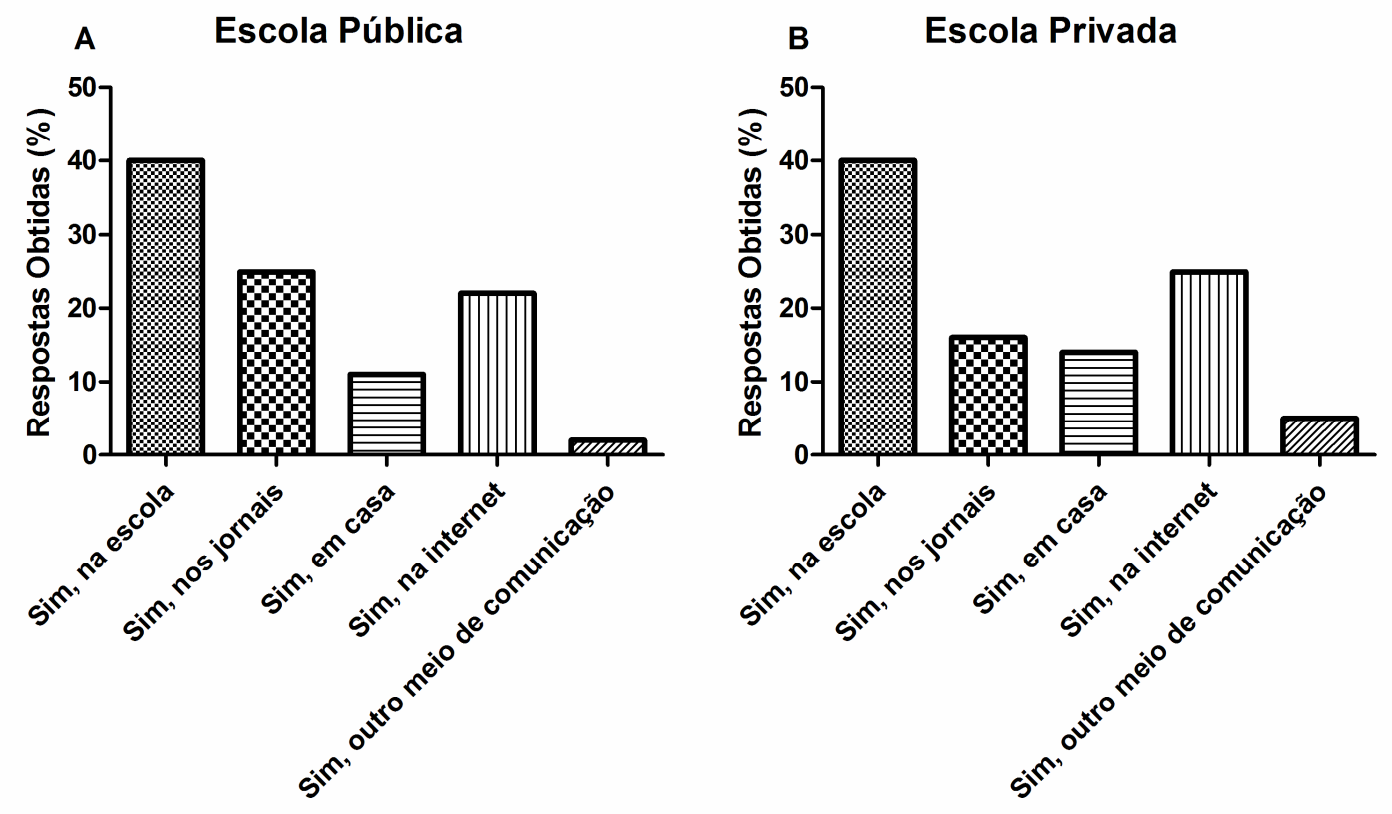

Figura 6: Gráfico correspondente às respostas dos alunos em relação à questão 07: Você já ouviu falar em coleta seletiva?

Também foi perguntado aos alunos, se existe coleta seletiva na cidade (questão 08). Como resposta, 49\% dos alunos da escola privada disseram que não existe coleta seletiva, e $42 \%$ dos alunos da escola pública não souberam informar, como mostra a figura 7, apesar do município de Bom Jesus do Itabapoana contar com locais de recolhimento de materiais recicláveis, o que nos mostra a falta de conhecimento desses alunos sobre a existência dos locais que realizam a coleta seletiva no município.

A falta de compreensão de alguns conceitos, detectadas nas respostas dos alunos, podem nos mostrar o reflexo da deficiência na formação destes alunos ou ao acesso a uma informação de baixa qualidade. Assim, a escola deveria se atentar para a realidade social do aluno auxilia-lo, fornecendo ferramentas que permitam que o mesmo interaja de maneira crítica e coerente com os problemas da realidade (BARBOSA, 2008). Deveria haver um trabalho de divulgação mais amplo, por parte dos órgãos públicos e das escolas, informando a toda sociedade que o município de Bom Jesus do Itabapoana possui um local destinado para a coleta seletiva.

Persp. online: hum. \& sociais aplicada., Campos dos Goytacazes, 15 (6),53-65, 2016

seer.perspectivasonline.com.br 

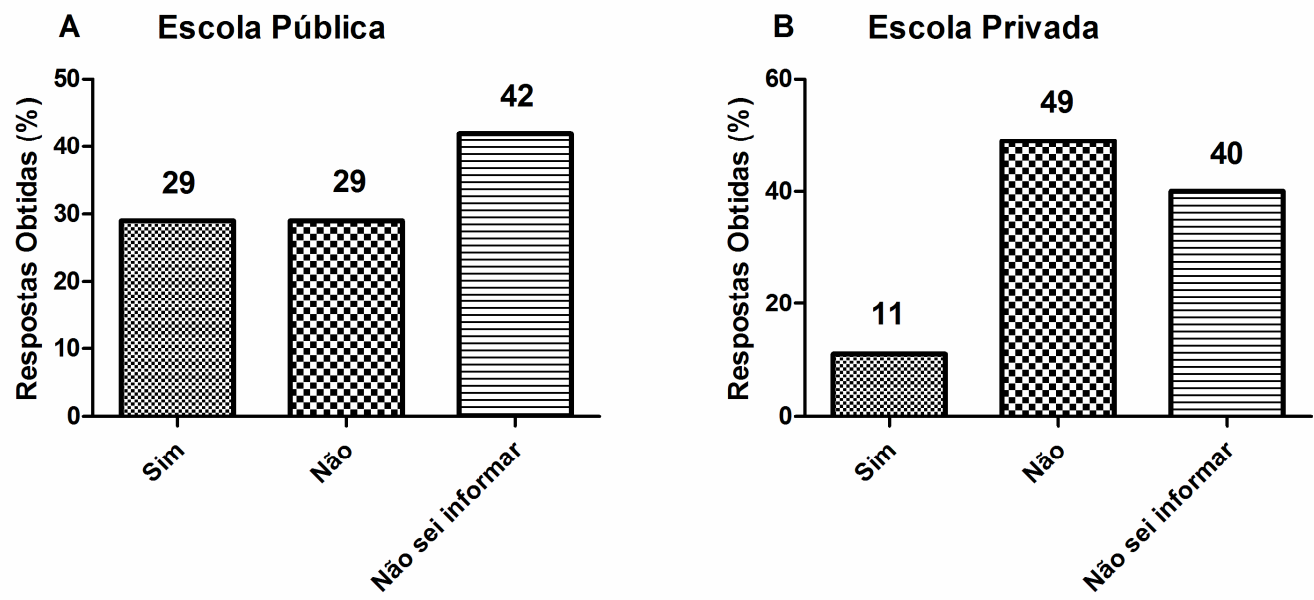

Figura 7: Gráfico correspondente às respostas dos alunos em relação à questão 08 : Na sua cidade existe a coleta seletiva?

Quando questionados aos alunos se em suas casas existe separação dos materiais recicláveis (questão 09), observamos que a maioria das famílias não apresenta o hábito de separar materiais para reciclagem, pois $83 \%$ dos alunos de escolas privadas responderam que não há separação de materiais recicláveis e $77 \%$ dos alunos da escola pública afirmaram o mesmo (dados não mostrados), o que nos remete a necessidade urgente da conscientização não só dos alunos, mas também da população local. A educação não deve se restringir apenas ao ambiente escolar, mas deve atingir a comunidade, fazendo-a entender que atitudes para amenizar a problemática do lixo através da reciclagem e da redução do consumo devem ser sempre realizadas, para que assim nós possamos observar mudanças no nosso cenário ambiental atual. Dohme \& Dohme (2002) afirmam que a educação necessita ocorrer de forma integrada e dinâmica, pois assim a comunidade e a escola possam colocar em prática atitudes que possam auxiliar a reverter a atual crise ambiental.

Quando perguntado aos alunos se o tema Lixo e/ou Reciclagem é abordado com freqüência nas salas de aula (questão 10), $58 \%$ dos alunos da rede pública e $48 \%$ da rede privada informaram que raramente o tema é abordado (figura 8). O professor não deveria ficar preso somente ao material didático, mas sim buscar alternativas que possam enriquecer o conhecimento dos alunos. Além disso, é essencial que as disciplinas se envolvam na problemática, e o tema reciclagem se torne comum no cotidiano dos alunos, independentemente da série ou do conteúdo, uma vez que isto deveria ser uma preocupação de todos, pois a Educação Ambiental é um tema universal e diz respeito à sobrevivência de todos nós (HERCULANO, 2006).

Quando indagados a onde estudam possui coleta seletiva (questão 11), cerca de $73 \%$ dos alunos da escola privada responderam que não existe coleta seletiva na escola, e $49 \%$ do alunos da escola pública responderam que não sabem informar (dados não mostrados). Na escola, podem-se criar formas adequadas de coleta e destino do lixo, reciclagem e reaproveitamento de materiais. É possível também, de acordo com os PCN, (1997) discutir em sala de aula o tipo de embalagens utilizadas nos produtos industrializados e as diversas formas de desperdício e o prejuízo causado por produtos descartáveis não-biodegradáveis. Porém, para isso, é necessário um melhor preparo dos profissionais envolvidos na educação, oferecendo cursos que possam

Persp. online: hum. \& sociais aplicada., Campos dos Goytacazes, 15 (6),53-65, 2016

seer.perspectivasonline.com.br 
capacitá-los estas pessoas, para que assim a sociedade possa colher frutos melhores no futuro (GUIMARÃES, 2006).

Nesse contexto, fica evidente a importância de se educar os cidadãos brasileiros para que, venham a agir de modo responsável e com sensibilidade, conservando o ambiente saudável no presente e para o futuro, para que saibam cumprir suas obrigações, exigir e respeitar os direitos próprios e os de toda a comunidade, tanto local como internacional, e, como pessoas, encontrem acolhidas para ampliar a qualidade de suas relações intra-e interpessoais com o ambiente tanto físico quanto social.
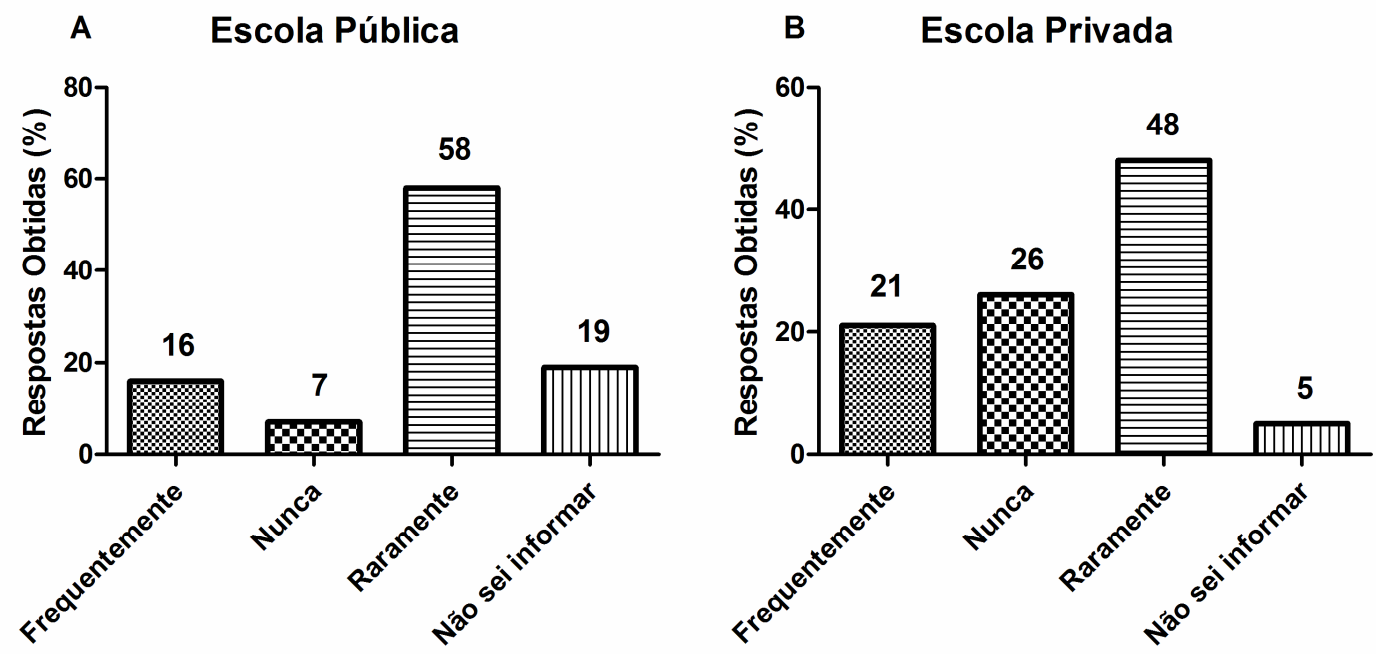

Figura 8: Gráfico correspondente às respostas dos alunos em relação à questão 10: Na sua escola, o tema LIXO e/ou Reciclagem é abordado com freqüência?

\section{CONCLUSÕES}

Apesar de o tema reciclagem ser cada vez mais significante para o desenvolvimento sustentável, os alunos mostraram não possuir um conhecimento muito aprofundado de tal tema.Os alunos recebem informações sobre o tema lixo e reciclagem através de diferentes fontes de comunicação, sendo escola a mais citada por eles. Porém, ainda são raros os projetos e trabalhos desenvolvidos pelas escolas, e ainda não há o envolvimento de toda a sua clientela. Como a escola é um local que busca a formação de cidadãos, cabe a ela buscar trabalhos que sensibilizem os alunos e a sociedade para questões ambientais graves.

Os temas Reciclagem e Lixo necessitam fazer parte dos temas transversais e serem, abordados em diversas disciplinas, para que estes façam parte do dia-a-dia dos alunos e a problemática seja percebida por aspectos e visões diferentes. É importante um trabalho em conjunto com todos os órgãos governamentais e com a sociedade em geral, pois a preocupação com o planeta e a sua degradação deve ultrapassar a segmentação das disciplinas, pois abrange conhecimentos necessários para a vida humana.

Desta forma, é necessário que as instituições de ensino se preocupem de maneira real para os grandes

Persp. online: hum. \& sociais aplicada., Campos dos Goytacazes, 15 (6),53-65, 2016

seer.perspectivasonline.com.br 
problemas que atingem cada vez mais o homem e que são ameaça iminente para as futuras gerações, que precisam ser despertadas para as sérias questões ambientais.

Não foram encontradas disparidades em relação ao conhecimento dos temas "lixo" e "reciclagem" pelos alunos do $9^{\circ}$ ano de Escolas públicas e privadas do município de Bom Jesus do Itabapoana, indicando que os temas devem ser mais abordados em ambos sistemas de ensino.

\section{REFERÊNCIAS BIBLIOGRAFICAS}

ABREU, L. B. \& PALhaRES, M. C. O destino do lixo. Trabalho de Estágio Supervisionado - professora Cristine Nogueira, Turma 2006.1 Disponível em file://C:/Users/Dell/Downloads/Lixo.pdf. Acesso em 30 set. 2010.

ALVES, R. Saiba mais sobre compostagem! Disponível em: http://www.rrr.cirp.usp.br/compostagem.html. Acesso em 07 de Julho 2011.

ANDRADE, C. Brasil produz 240 mil toneladas de lixo por dia. Jornal E-BAND, edição de 5 de junho de 2010. Disponível em: http://www.band.com.br/jornalismo/cidades/conteudo.asp?ID=311480. Acesso em 05 de Abril 2011.

BARBOSA, F. E. Percepção dos alunos de Escolas Públicas do Município de Bom Jesus do Itabapoana/RJ em Relação à Problemática do Lixo. Monografia Apresentada na Universidade Estadual do Norte Fluminense Darcy Ribeiro como parte das exigências para obtenção do grau de Licenciado no curso de Licenciatura em Ciências Biológicas do Consórcio CEDRJ - modalidade à distância - UENF/CEDERJ, 2008.

BURGIERMAN, D. R. A terceira fronteira. Sustentável é pouco: Idéias e experiências que vão além do discurso da sustentabilidade, 2010. Disponível em: http://veja.abril.com.br/blog/denis-russo/consumo/a-terceirafronteira/

MUCElin, C. A.; Bellini, M. Lixo E Impactos Ambientais Perceptíveis No Ecossistema Urbano, Sociedade \& Natureza, Uberlândia, 20 (1): 111-124, jun. 2008

CRUZ, I. \& MARQUES, F. O lixo através da história. Revista de Manguinhos, edição de setembro de 2007. Disponível em: http://www.fiocruz.br/ccs/media /pag\%2040-41\%20-\%20lixo. Pdf. Acesso em 04 out. 2010.

DEBORTOLI, R \& BORBA, J. A. Análise do Tratamento dos Resíduos Sólidos e dos Benefícios Ambientais e Econômicos da Coleta Seletiva: o caso dos catadores de Biguaçú-SC. Congresso USP de Iniciação Científica em Contabilidade, 2006.

DOHME, V. \& DOHME, W. Ensinando a criança a amar a natureza. 3 Ed. São Paulo:Informal, (2002).

ESREY, S. A.; POTASH, J. B.; ROBERTS, L. \& SHIFF, C., 1991. Effects of improved water supply and sanitation on ascariasis, diarrhoea, dracunculiasis, hookworm infection, schistosomiasis and trachoma. Bulletin of the World Health Organization, Vol.69, p.609-621.

FADINI. P. S. \& FADINI, A. A. B. Lixo: desafios e compromissos. Cadernos Temáticos de Química Nova na Escola. Ed. Especial, p.9-18, 2001.

FILHO, B, J. Compostagem: a utilização econômica e ecológica do lixo orgânico. Portal Amazônia, Disponível em: http://portalamazonia.globo.com/pscript/artigos/artigo.php?idArtigo=284, acessado em 11 Julho 2011.

Persp. online: hum. \& sociais aplicada., Campos dos Goytacazes, 15 (6),53-65, 2016

seer.perspectivasonline.com.br 
FILHO, H. M. V. Plástico: Descrição e Análise do Ciclo de Reciclagem. Monografia de graduação do Centro de Ciências Sociais - CCS, Departamento de Geografia e Meio Ambiente, Pontifícia Universidade Católica do Rio de Janeiro, julho de 2006.

GADOTTI, M. Perspectivas Atuais da Educação. Disponível em: http://www.scielo.br/pdf/spp/v14n2/9782.pdf. Acesso em 25 de Novembro 2010.

GREENPEACE, 2007. Guia de Ahorro de Energia. Disponível em: http://www.greenpeace.org/raw/content/mexico/prensa/reports/gu-a-de-ahorro-de-energ -a.pdf, acessado em $31 / 05 / 2011$.

GUIMARÃES, M. Educação ambiental pra quê? In: SENAC. Textos complementares do bloco temático IV. Brasília: E-BOOK do curso de educação ambiental, 2006.

GUIMARÃES, P. Lixo urbano: Potencial de aproveitamento energético de resíduos orgânicos. Disponível em: http://www.ecodebate.com.br/2011/03/22/lixo-urbano-potencial-de-aproveitamento-energetico-dos-residuosorganicos-artigo-de-patricia-guimaraes/. Acesso em 02 de Julho 2011.

GUSMÃO, K. O Noroeste Fluminense Será Beneficiado Com Criação de Aterros Sanitários, Notícias de Fato.com. 2010. Disponível em: http://www.noticiasdefato.com/archives/o-noroeste-zfluminense-serabeneficiado-com-a-criacao-de-aterros-sanitarios. Acesso em 02 de Abril 2011

HENDGES, S.A. Os quatro "Rs" e a Política Nacional de Resíduos Sólidos. Revista Ecológica. Disponível em: http://www.revistaecologica.com/index.php?option=com_content \&view=article\&id=889:os-quatro-qrsq-ea-politica-nacional-de-residuos-solidos-artigo-de-antonio-silvio-hendges\&catid=101:sustentabilidade, Acesso em 12/07/2011.

HERCULANO, S. C. A consciência da solidariedade. In: SENAC. Textos complementares do bloco temático IV. Brasília: E-book do Curso de Educação Ambiental, 2006.

IBGE. Cuidando do Lixo. Disponível em: http://www.ibge.gov.br/ibgeteen/datas/gari/cuidando.html, 2000. Acesso em 20 de Março 2011.

IBGE. Dados Publicados no Diário Oficial da União. Disponível em: http://www.censo2010.ibge.gov.br/dados_divulgados/index.php?uf=33, 2010. Acesso em 15 de Abril 2011.

LIMA, M. Um bebê $=\mathbf{2 5}$ toneladas de lixo. Revista Veja ambiente on-line. Disponível em: http://veja.abril.com.br/170399/p_060.html. Acesso em 17 mar. 1999.

MARONDIN, V. S.; BARBA, I. S.; MORAIS, G. A. Educação Ambiental com os Temas Geradores de Lixo e Água e a Confeç̧ão de Papel Reciclável Artesanal. Anais do $2^{\circ}$ Congresso Brasileiro de Extensão Universitária. Belo Horizonte, 12 a 15 de setembro de 2004.

MENDONÇA, F. \& KOZEL, S. (Org.). Elementos de Epistemologia da geografia a contemporânea. Curitiba: UFPR, 2002.

Persp. online: hum. \& sociais aplicada., Campos dos Goytacazes, 15 (6),53-65, 2016

seer.perspectivasonline.com.br 
MINISTÉRIO DO MEIO AMBIENTE (acesso 11/11/2014) http://www.mma.gov.br/responsabilidadesocioambiental/item/9410-a-pol\%C3\%ADtica-dos-5-r-s

NASCIMENTO, R. I. Recolhimento de Embalagens pela Indústria, através de um Programa de Educação Ambiental: Estudo de Caso. VI Congresso Nacional de Excelência em Gestão. Disponível em: http://www.excelenciaemgestao.org/Portals/2/documents/cneg6/anais/T10_0239_1108.pdf, acesso em $12 / 07 / 2011$.

GOUVEIA, N.; PRADO, R. R. Riscos à saúde em áreas próximas a aterros de resíduos sólidos urbanos, Rev Saúde Pública 2010;44(5):859-66

PARÂMETROS CURRICULARES NACIONAIS: Meio ambiente saúde / Secretaria de Educação Fundamental. - Brasília: pp. 23, 36, 224. 1997

ROBINSON, L. Southern Sydney Waste Planning and Management Board, Social Change Media ACN 104 663 498, 1998. Disponível em http://www.media.socialchange.net.au/recycling/; acessado em 25/05/2011.

RUDEK, C. G. \& MUZZILLO, C. S. O Inicio da abordagem ambiental nos planos de desenvolvimento urbano brasileiro a partir da preocupação mundial em busca do desenvolvimento sustentável. Akropólis, Umuarama, v.15, n.1 e 2 , p. 11-18, 2007.

SAKER. F. Lixo é matéria-prima para energia elétrica. Revista Brasileira de Bioenergia. Disponível em: http://cenbio.iee.usp.br/destaques/2010/RBB9.htm. Acesso em 02 de Julho 2011.

SEGURA, D.S. . Educação ambiental na escola pública: da curiosidade ingênua à consciência crítica. São Paulo: Annablume/FAPESP, 2001.

SILVÉRIO, S. Brasil terá que trocar lixão por aterro até 2015. Disponível em: http://lidebrasil.com.br/site/index.php/2010/11/08/brasil-tera-de-trocar-lixao-por-aterro-sanitario-ate-2015.

Acesso em 15 de Janeiro de 2011.

TCE. Estudo Socioeconômico de Bom Jesus do Itabapoana. Tribunal de Contas do Estado do Rio de Janeiro: Secretaria Geral de Planejamento,2005.

VENTURA, M. O que fazer com o lixo. Disponível em: http://veja.abril.com.br/especiais/ ecologia_2002/reciclagem.html. Acesso em 27 de Abril 2011.

WEINBERG, M. Comece a Reciclar. Revista Abril Setembro 2007 Disponível em: http://veja.abril.com.br/050907/p_118.shtml. Acesso em 22 de Abril 2011.

ZANI, L. A arte de reutilizar. Manual de atividades Plásticas Disponível em: http://www.luciazani.pt/Slides5R.pdf. Acesso em 02 Julho 2011.

Persp. online: hum. \& sociais aplicada., Campos dos Goytacazes, 15 (6),53-65, 2016

seer.perspectivasonline.com.br 